DOI https://doi.org/10.30525/978-9934-26-008-7.2-10

\title{
MICROWAVE WAVEGUIDE POLARIZERS OPTIMIZATION IN FREQUENCY AND TIME DOMAINS
}

\author{
Piltyay S. I., Bulashenko A. V.
}

\section{INTRODUCTION}

Nowadays, microwave waveguide polarizers ${ }^{1}$ are fundamental devices in modern radar $^{2}$ and satellite telecommunication antenna systems ${ }^{3}$, which receive and transmit the signals with orthogonal circular polarizations of electromagnetic waves ${ }^{4}$. A polarizer ${ }^{5}$ determines the performance of polarizations transformation ${ }^{6}$ of waveguide feed network of the antenna system ${ }^{7}$. Thus, accurate calculation of the phase and polarization characteristics of modern waveguide polarizers is of crucial importance. All waveguide polarizers can be divided into three groups. Many various scientific articles and conference papers are dedicated to

${ }^{1}$ Piltyay S.I., Sushko O.Yu., Bulashenko A.V., et al. Compact Ku-band iris polarizers for satellite telecommunication systems. Telecomm. and Radio Eng. 2020. Vol. 79, No. 19. P. 1673-1690. DOI: 10.1615/TelecomRadEng.v79.i19.10.

2 Piltyay S.I., Bulashenko A.V., Demchenko I.V. Analytical synthesis of waveguide iris polarizers. Telecomm. and Radio Engineering. 2020. Vol. 79, No. 18. P. 1579-1597. DOI: 10.1615/TelecomRadEng.v79.i18.10.

${ }^{3}$ Piltyay S I., Bulashenko A.V., Demchepnko I.V. Waveguide iris polarizers for Ku-band satellite antenna feeds. Journal of Nano- and Electronic Physics. 2020. Vol. 12, No. 5. P. 05024-1-5. DOI: 10.21272/jnep.12(5).05024.

${ }^{4}$ Bulashenko A.V., Piltyay S.I., Demchenko I.V. Optimization of a polarizer based on a square waveguide with irises. Science-Based Technologies. 2020. Vol. 47, No. 3. P. 287-297. DOI: 10.18372/2310-5461.47.14878.

${ }^{5}$ Piltyay S.I., Bulashenko A.V., Demchenko I.V. Compact polarizers for satellite information systems. IEEE Int. Conf. on Problems of Infocommunications. Science and Technology (PIC S\&T). Kharkiv, Ukraine, 2020. Pp. 350-355.

${ }^{6}$ Bulashenko A.V., Piltyay S.I., Demchenko I.V. Analytical technique for iris polarizers development. IEEE Int. Conf. on Problems of Infocommunications. Science and Technology (PIC S\&T). Kharkiv, Ukraine, 2020. P. 464-469.

${ }^{7}$ Piltyay S.I. High performance extended C-band 3.4-4.8 GHz dual circular polarization feed system. XI International Conference on Antenna Theory and Techniques (ICATT). Kyiv, 2017. P. 284-287. DOI: 10.1109/ICATT.2017.7972644. 
the development and optimization of waveguide iris polarizers ${ }^{8}$, post polarizers and septum polarizers ${ }^{9}$. A septum in the structure of the polarizer can have stepped ${ }^{10}$ or constant thickness ${ }^{11}$.

In dual polarization antenna systems' a polarizer operates in combination with an orthomode transducer. Its function in a receiving antenna is the separation of signals with orthogonal linear polarizations to isolated channels. In a transmitting antenna it combines signals with orthogonal linear polarizations into a common channel.

Many modern scientific publications present the results of development and analysis of new designs of polarizers ${ }^{12}$ and orthomode transducers $^{13}$. Wideband orthomode transducers are based on highly symmetrical quad-ridged waveguides, double-ridged transitions in square waveguides and turnstile junctions ${ }^{14}$.

Dual-band antenna systems with double circular polarizations require the implementation of coaxial horn feeds, coaxial polarizers and dualband orthomode transducers ${ }^{15}$ based on the coaxial quad-ridged

8 Dubrovka F.F., Piltyay S.I. A novel wideband coaxial polarizer. IX International Conference on Antenna Theory and Techniques (ICATT). Odessa, Ukraine, 2013. Pp. 473-474. DOI: 10.1109/ICATT.2013.6650816.

${ }^{9}$ Dubrovka F., et al. Circularly polarised X-band H11- and H21-modes antenna feed for monopulse autotracking ground station. IEEE UkrMW. Kharkiv, Ukraine, 2020. Pp. 196-202. DOI: 10.1109/UkrMW49653.2020.9252600.

${ }^{10}$ Dubrovka F., Piltyay S., Sushko O., et al. Compact X-band stepped-thickness septum polarizer. IEEE Ukrainian Microwave Week (UkrMW). Kharkiv, Ukraine, 2020, Pp. 135-138. DOI: 10.1109/UkrMW49653.2020.9252583.

${ }^{11}$ Dubrovka F.F., Piltyay S.I., et al. Optimum septum polarizer design for various fractional bandwidths. Radioelectronics and Communications Systems. 2020. Vol. 63, No. 1. P. 15-23. DOI: 10.3103/S0735272720010021.

${ }^{12}$ Bulashenko A.V., Piltyay S.I., et al. Tunable square waveguide polarizer with irises and posts. Technical Engineering. 2020. Vol. 86, Mo. 2. P. 108-116. DOI: 10.26642/ten-2020-2(86)-108-116.

13 Dubrovka F.F., Piltyay S.I. A high performance ultrawideband orthomode transducer and a dual-polarized quad-ridged horn antenna based on it. VIII International Conference on Antenna Theory and Techniques (ICATT). Kyiv, Ukraine, 2011, Pp. 176-178. DOI: 10.1109/ICATT.2011.6170737.

${ }^{14}$ Dubrovka F.F., Piltyay S.I. Novel high performance coherent dual-wideband orthomode transducer for coaxial horn feeds. XI Int. Conf. on Antenna Theory \& Tech. Kyiv, Ukraine, 2017. Pp. 277-280. DOI: 10.1109/ICATT.2017.7972642.

${ }^{15}$ Piltyay S.I. Enhanced C-band coaxial orthomode transducer. Visnyk NTUU KPI. Seriia - Radiotekhnika, Radioaparatobuduvannia. 2014. Vol. 58. P. 27-34. DOI: 10.20535/RADAP.2014.58.27-34. 
waveguides $^{16}$ and sectoral coaxial ridged waveguides ${ }^{17}$. Theoretical analysis of electromagnetic eigenmodes ${ }^{18}$ in such structures is relatively complicated $^{19}$ and it is carried out using the transverse field-matching technique $^{20}$ or by the integral equation technique ${ }^{21}$. Obtained results ${ }^{22}$ allow to chose the sizes of coaxial ridged waveguides ${ }^{23}$ for the specified operating bands ${ }^{24}$.

Various numerical techniques are applied for the development and optimization of the polarization processing microwave devices. Namely, we can highlight many modifications of finite difference time domain (FDTD) technique and of finite elements method (FEM) in the frequency domain. An actual problem is the comparison of different material

16 Dubrovka F.F., Piltyay S.I. Eigenmodes of coaxial quad-ridged waveguides. Numerical results. Radioelectronics and Communications Systems. 2014. Vol. 57, No. 2. P. 59-69. DOI: 10.3103/S0735272714020010.

${ }^{17}$ Dubrovka F.F., Piltyay S.I. Eigenmodes of sectoral coaxial ridged waveguides. Radioelectronics and Communications Systems. 2012. Vol. 55, No. 6. P. 239-247. DOI: 10.3103/S0735272712060015.

${ }^{18}$ Dubrovka F.F., Piltyay S.I. Eigenmodes of coaxial quad-ridged waveguides. Theory. Radioelectronics and Communications Systems. 2014. Vol. 57, No. 1. P. 1-30. DOI: 10.3103/S0735272714010014.

${ }^{19}$ Dubrovka F.F., Piltyay S.I. Electrodynamics boundary problem solution for sectoral coaxial ridged waveguides by integral equation technique. Radioelectronics and Communications Systems. 2012. Vol. 55, No. 5. P. 191-203. DOI: 10.3103/S0735272712050019.

${ }^{20}$ Piltyay S.I., Dubrovka F.F. Eigenmodes analysis of sectoral coaxial ridged waveguides by transverse field-matching technique. Part 1. Theory. Visnyk NTUU KPI. Seriia - Radiotekhnika, Radioaparatobuduvannia. 2013. Vol. 54. P. 13-23. DOI: 10.20535/RADAP.2013.54.13-23.

21 Piltyay S.I. Numerically effective basis functions in integral equation technique for sectoral coaxial ridged waveguides. 14-th International Conference on Mathematical Methods in Electromagnetic Theory (MMET). Kyiv, Ukraine, 2012. P. 492-495. DOI: 10.1109/MMET.2012.6331195.

${ }^{22}$ Dubrovka F.F., Piltyay S.I. Eigenmodes analysis of sectoral coaxial ridged waveguides by transverse field-matching technique. Part 2. Numerical results. Visnyk NTUU KPI. Seriia - Radiotekhnika, Radioaparatobuduvannia. 2013. Vol. 55. P. 13-23. DOI: 10.20535/RADAP.2013.55.13-23.

${ }^{23}$ Dubrovka F.F., Piltyay S.I. Boundary problem solution for eigenmodes in coaxial quad-ridged waveguides. Information and Telecommunication Sciences. 2014. Vol. 5, No. 1. P. 48-61. DOI: 10.20535/2411-2976.12014.48-61.

${ }^{24}$ Dubrovka F.F., Piltyay S.I. Prediction of eigenmodes cutoff frequencies of sectoral coaxial ridged waveguides. Proceedings of International Conference on Modern Problem of Radio Engineering, Telecommunications and Computer Science (TCSET). Lviv-Slavske, Ukraine, 2012. P. 191. 
averaging approaches in the finite integration technique (FIT) for curved dielectrics.

Recently, scientists optimized the subgrid connection for space-time FIT $^{25}$. Suggested numerical optimization technique ${ }^{26}$ provides highly effective reduction of unphysical wave reflections ${ }^{27}$. Some articles suggested the modification of FEM for computing the anisotropic and open waveguide modes ${ }^{28}$. Numerical examples verify that the proposed mixed FEM is free of spurious eigenmodes and ensures high numerical efficiency. The application of new nonconformal hybrid FDTD/FETD ${ }^{29}$ allows to eliminate the undesired hybridization through a buffer zone. Numerical examples confirm highly effective performance of the recommended hybrid method.

Fundamental problem for the development of modern microwave waveguide polarizers is high sensitivity of their polarization characteristics to the inaccuracies of calculation of optimal parameters and to the tolerances of manufacture technology. Thus, the determination of the best suitable numerical technique for highly accurate calculation and optimization of all electromagnetic characteristics of microwave waveguide polarizers remains an important scientific and engineering problem. The results of performed in this article researches provide the recommendations on which numerical method is faster and more accurate for the analysis, development and optimization of waveguide polarizers for radar and satellite information systems.

${ }^{25}$ Sakata Y., Mifune T., Matsuo T. Optimal subgrid connection for space-time finite integration technique. IEEE Transactions on Magnetics. 2017. Vol. 53, No. 6. DOI: 10.1109/TMAG.2017.2655626.

${ }^{26}$ Sakata Y., Mifune T., Matsuo T. Optimal subgrid connection for space-time finite integration technique. IEEE Conference on Electromagnetic Field Computation (CEFC), P. 1, 2016. DOI: 10.1109/CEFC.2016.7816159.

${ }^{27}$ Naydenko V., Piltyay S. Evolution of radiopulses radiated by Hertz's dipole in vacuum. 12-th International Conference on Mathematical Methods in Electromagnetic Theory (MMET). Odessa, Ukraine, 2008. P. 494-497. DOI: 10.1109/MMET.2008.4580972.

${ }^{28}$ Liu N., Cai G., Zhu C., et al. The mixed finite element method with mass lumping for computing optical waveguide modes. IEEE Journal of Selected Topics in Quantum Electronics. 2015. Vol. 22(2). DOI: 10.1109/JSTQE.2015.2473689.

29 Sun Q., et al. 3-D implicit-explicit hybrid finite difference/spectral element/finite element time domain method without a buffer zone. IEEE Trans. on Antennas and Propagation. 2019. Vol. 67(8). DOI: 10.1109/TAP.2019.2913740. 


\section{Waveguide iris polarizer, its phase and polarization characteristics}

Modern wideband radar and satellite systems, which apply signals with dual orthogonal circular polarizations, include waveguide iris polarizers $^{30}$. The polarizer of such type is a compact microwave device, that transforms two orthogonal circularly polarized electromagnetic waves into two orthogonal electromagnetic waves with linear polarizations. The typical design of waveguide iris polarizer is shown in Fig. 1. Shown polarizer is based on a square waveguide with 5 symmetrical irises in it.

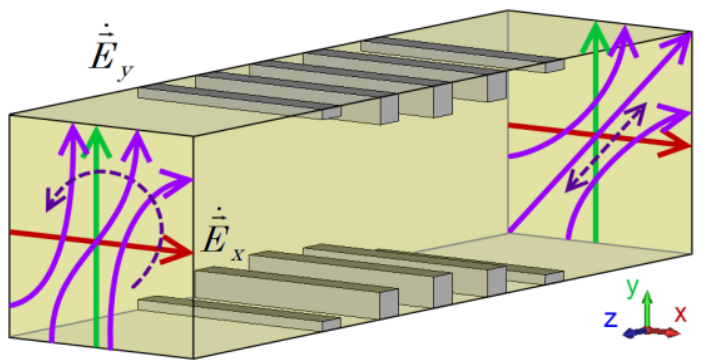

Fig. 1. The structure of a square waveguide polarizer with 5 irises and transformation of fundamental electromagnetic modes polarization in it

Two fundamental electromagnetic modes of a square waveguide are $\mathrm{TE}_{10}$ and $\mathrm{TE}_{01}$. They have orthogonal linear polarizations and propagate along the longitudinal $\mathrm{z}$ axis of the polarizer. Electric field phasors of the fundamental modes are as follows:

$$
\dot{\vec{E}}_{x}=A e^{i \phi_{A}} \vec{e}_{x} ; \dot{\vec{E}}_{y}=B e^{i \phi_{B}} \vec{e}_{y},
$$

where $A$ and $B$ are the magnitudes of electric fields oriented along $\mathrm{x}$ and y axes, respectively. $\varphi_{A}$ and $\varphi_{B}$ are the initial phases of electromagnetic modes at the output. Let us denote central phase and phase difference as:

$$
\phi_{0}=\left(\phi_{A}+\phi_{B}\right) / 2 ; \Delta \phi=\phi_{B}-\phi_{A} .
$$

${ }^{30}$ Bulashenko A. V. , Piltyay S. I. Equivalent microwave circuit technique for waveguide iris polarizers development. Visnyk NTUU KPI Seriia Radiotekhnika Radioaparatobuduvannia. 2020. Vol. 83. P. 17-28. DOI: 10.20535/RADAP.2020.83.17-28. 
Then the initial phases can be rewritten as follows:

$$
\phi_{A}=\phi_{0}-\Delta \phi / 2 ; \phi_{B}=\phi_{0}+\Delta \phi / 2 \text {. }
$$

Now we substitute formulas (2) in (1) and consider the superposition of modes:

$$
\dot{\vec{E}}_{\Sigma}=\dot{\vec{E}}_{x}+\dot{\vec{E}}_{y}=A e^{i\left(\phi_{0}-\Delta \phi / 2\right)} \vec{e}_{x}+B e^{i\left(\phi_{0}+\Delta \phi / 2\right)} \vec{e}_{y}=e^{i \phi_{0}}\left(A e^{-i \Delta \phi / 2} \vec{e}_{x}+B e^{i \Delta \phi / 2} \vec{e}_{y}\right) .
$$

Let us define projections $\dot{C}$ and $\dot{D}$ of phasor (3) in a circular polarization basis:

$$
A e^{-i \Delta \phi / 2} \vec{e}_{x}+B e^{i \Delta \phi / 2} \vec{e}_{y}=\dot{C}\left(\vec{e}_{x}+i \cdot \vec{e}_{y}\right)+\dot{D}\left(\vec{e}_{x}-i \cdot \vec{e}_{y}\right) .
$$

We have obtained a set of linear equations with unknown values $\dot{C}$ and $\dot{D}$ :

$$
\left\{\begin{array}{c}
\dot{C}+\dot{D}=A e^{-i \Delta \phi / 2} \\
\dot{C}-\dot{D}=-i B e^{i \Delta \phi / 2}
\end{array}\right.
$$

Having solved set of equations (4), we obtain the phasors $\dot{C}$ and $\dot{D}$ as follows:

$$
\begin{aligned}
& \dot{C}=\frac{1}{2}\left(A \cos \frac{\Delta \phi}{2}-i A \sin \frac{\Delta \phi}{2}-i B \cos \frac{\Delta \phi}{2}+B \sin \frac{\Delta \phi}{2}\right) ; \\
& \dot{D}=\frac{1}{2}\left(A \cos \frac{\Delta \phi}{2}-i A \sin \frac{\Delta \phi}{2}+i B \cos \frac{\Delta \phi}{2}-B \sin \frac{\Delta \phi}{2}\right) .
\end{aligned}
$$

Now we can determine the amplitudes of the phasors $\dot{C}$ and $\dot{D}$ :

$$
\begin{aligned}
& |\dot{C}|=\frac{1}{2} \sqrt{A^{2}+B^{2}+2 A B \sin \Delta \phi} \\
& |\dot{D}|=\frac{1}{2} \sqrt{A^{2}+B^{2}-2 A B \sin \Delta \phi} .
\end{aligned}
$$

In circular polarization basis the axial ratio is defined from the $\operatorname{expression}^{31}$ :

$$
r=(|\dot{C}|+|\dot{D}|) /(|\dot{C}|-|\dot{D}|) .
$$

Now we substitute (5) and (6) into the squared (7) and obtain the expression:

${ }^{31}$ Milligan T.A. Modern Antenna Design. Hoboken, New Jersey : John Wiley and Sons, 2005. 614 p. 


$$
r^{2}=\frac{A^{2}+B^{2}+\sqrt{A^{4}+B^{4}+2 A^{2} B^{2} \cos (2 \Delta \phi)}}{A^{2}+B^{2}-\sqrt{A^{4}+B^{4}+2 A^{2} B^{2} \cos (2 \Delta \phi)}} .
$$

In decibel scale the formula (8) for the calculation of axial ratio is as follows:

$$
r(\mathrm{~dB})=10 \lg \frac{A^{2}+B^{2}+\sqrt{A^{4}+B^{4}+2 A^{2} B^{2} \cos (2 \Delta \phi)}}{A^{2}+B^{2}-\sqrt{A^{4}+B^{4}+2 A^{2} B^{2} \cos (2 \Delta \phi)}} .
$$

Another frequently applied characteristic of polarization state of electromagnetic waves, which is equivalent to axial ratio, is crosspolar discrimination (XPD). Usually XPD is expressed in $\mathrm{dB}$ and can be calculated from axial ratio (8) or (9) as follows:

$$
\mathrm{XPD}(\mathrm{dB})=20 \lg \left(\frac{r+1}{r-1}\right),
$$

where $r$ is the axial ratio (9), which preliminary must be translated into linear scale.

For the numerical optimization of a square waveguide iris polarizer the axial ratio (9) and XPD (10) at the polarizer's output were simultaneously analyzed along with differential phase shift and VSWR for fundamental modes of both polarizations. The goal functions of optimization were VSWR for both fundamental modes less than 1.15 and XPD higher than $32 \mathrm{~dB}$ in the operating Ku-band 10.7-12.8 GHz. The characteristics of the optimized design of developed polarizer are shown in Fig. 2-5. They were calculated with high accuracy by FEM in frequency domain using 100000 tetrahedral mesh cells, at which the inner volume of the structure was divided.

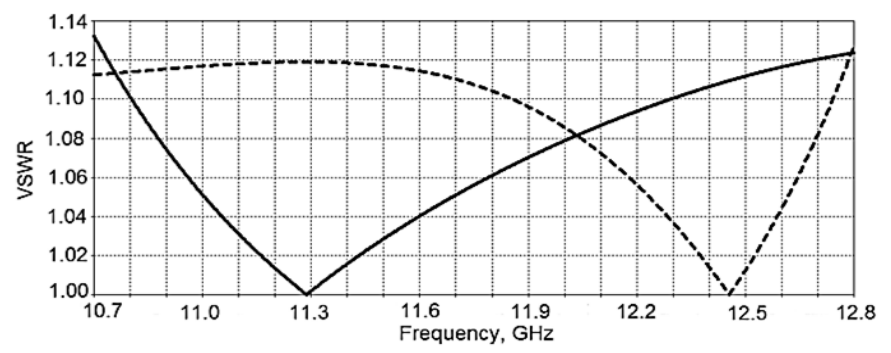

Fig. 2. VSWR of optimized waveguide iris polarizer for both polarizations horizontal polarization; - - - vertical polarization 
It is seen in Fig. 2 that in the operating Ku-band $10.7-12.8 \mathrm{GHz}$ the VSWR for fundamental modes of both horizontal and vertical polarizations is less than 1.13 , which fully satisfies the requirements. Fig. 3 demonstrates that the differential phase shift of the optimized design of waveguide iris polarizer varies from $87.5^{\circ}$ to $92.5^{\circ}$.

Axial ratio of the polarizer was obtained using the FEM simulation results and the formula (9). It is seen in Fig. 4 that the axial ratio of the optimized polarizer is less than $0.40 \mathrm{~dB}$ in the operating frequency band 10.7-12.8 GHz. The corresponding XPD was calculated using the formula (10). In Fig. 5 we observe that in the operating Ku-band 10.7$12.8 \mathrm{GHz}$ XPD of the optimized polarizer design is higher than $32 \mathrm{~dB}$.

In the next chapter we will investigate the frequency dependences of matching, phase and polarization characteristics on the number of tetrahedral mesh cells, which were applied for the numerical calculation by FEM. In addition, we will compare the obtained results with the ones calculated by FDTD using hexahedral mesh cells.

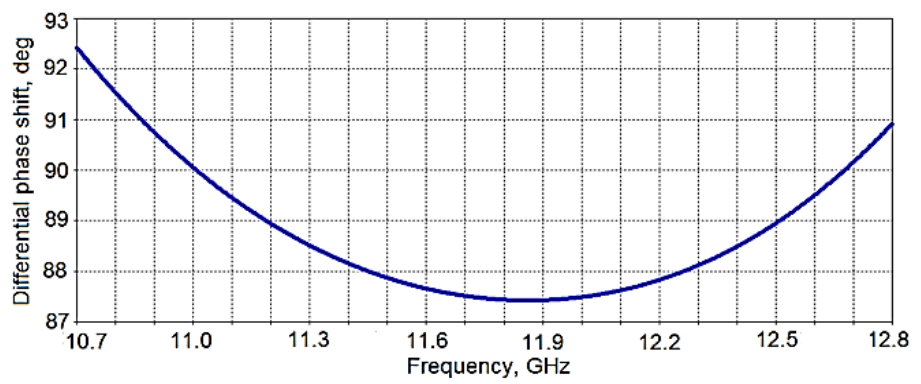

Fig. 3. Differential phase shift of the optimized square waveguide iris polarizer

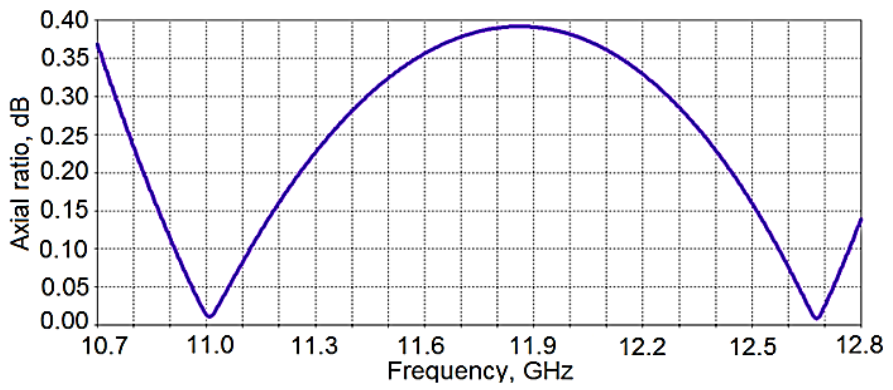

Fig. 4. Axial ratio of the optimized square waveguide iris polarizer 


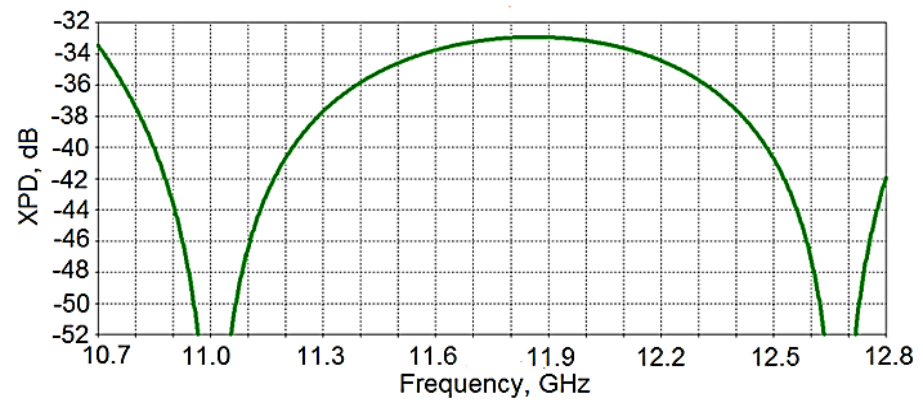

Fig. 5. XPD of the optimized square waveguide polarizer with 5 irises

\section{Numerical simulation of waveguide iris polarizer using FEM in the frequency domain with different number of tetrahedral mesh cells}

Results of numerical simulations by FEM were obtained for the number of tetrahedral mesh cells from 20000 to 200000 . The increment step of tetrahedral mesh was 20000 mesh cells. The calculated matching and polarization performance of the same design of square waveguide iris polarizer as functions of the number of used tetrahedral mesh cells and computation time are presented in Table 1. Analysis of Table 1 shows that the dependence of computation time on the number of used in FEM tetrahedral mesh cells is approximately linear function. In this case we observe that the convergence of VSWR is very fast. Therefore, the calculation of VSWR of microwave devices using FEM is very accurate even at coarse tetrahedral grids. At the coarse grid with 20000 tetrahedral mesh cells the VSWR maximum level is approximately 1.136 and it converges to the value of 1.132 for the dense grids. Consequently, for more dense grids the maximum level of VSWR slightly decreases.

It is seen in Table 1 that at coarse grids the calculation of phase and polarization characteristics of a waveguide iris polarizer is quite inaccurate. Although the polarizer provides the required XPD higher than $32 \mathrm{~dB}$, the results of calculations by FEM at coarse grids 20000 40000 mesh cells predict XPD levels of only 29-31 dB.

In Table 1 we can see that the increase of the number of tetrahedral mesh cells from 20000 to 100000 results in the decrease of axial ratio of the polarizer from $0.60 \mathrm{~dB}$ to $0.37 \mathrm{~dB}$. Simultaneously, XPD of the polarizer increases from $29.2 \mathrm{~dB}$ to $33.1 \mathrm{~dB}$. Further increase of the number of tetrahedral mesh cells from 100000 to 200000 results in the 
increase of axial ratio of the developed polarizer from $0.37 \mathrm{~dB}$ to $0.40 \mathrm{~dB}$ and in the simultaneous decrease of its XPD from $33.1 \mathrm{~dB}$ to $32.5 \mathrm{~dB}$.

Fig. 6-8 demonstrate the results of numerical calculation of the phase and polarization characteristics of the developed square waveguide iris polarizer using FEM in the frequency domain. In these figures we see the comparison of the results obtained using the coarse tetrahedral grid with 20000 mesh cells with the numerical results found using the moderate grid with 100000 tetrahedrons and with the ones calculated using the dense tetrahedral grid with 200000 mesh cells.

Table 1

Characteristics of optimized waveguide polarizer and computation time vs. the number of tetrahedral mesh cells applied in FEM in the frequency domain

\begin{tabular}{|c|c|c|c|c|c|}
\hline $\begin{array}{c}\text { Number of } \\
\text { tetrahedral } \\
\text { mesh cells }\end{array}$ & $\begin{array}{c}\text { Computation } \\
\text { time of FEM, } \\
\text { seconds }\end{array}$ & $\begin{array}{c}\text { Maximum } \\
\text { level of } \\
\text { VSWR }\end{array}$ & $\begin{array}{c}\text { Differential } \\
\text { phase shift, }\end{array}$ & $\begin{array}{c}\text { Axial } \\
\text { ratio, } \\
\text { dB }\end{array}$ & $\begin{array}{c}\text { XPD, } \\
\text { dB }\end{array}$ \\
\hline 20000 & 28 & 1.136 & $90^{\circ} \pm 3.95^{\circ}$ & 0.60 & 29.2 \\
\hline 40000 & 46 & 1.134 & $90^{\circ} \pm 3.11^{\circ}$ & 0.47 & 31.3 \\
\hline 60000 & 64 & 1.133 & $90^{\circ} \pm 2.77^{\circ}$ & 0.42 & 32.3 \\
\hline 80000 & 76 & 1.133 & $90^{\circ} \pm 2.62^{\circ}$ & 0.40 & 32.8 \\
\hline 100000 & 100 & 1.132 & $90^{\circ} \pm 2.51^{\circ}$ & 0.39 & 33.1 \\
\hline 120000 & 117 & 1.132 & $90^{\circ} \pm 2.55^{\circ}$ & 0.39 & 33.0 \\
\hline 140000 & 139 & 1.132 & $90^{\circ} \pm 2.60^{\circ}$ & 0.40 & 32.8 \\
\hline 160000 & 172 & 1.132 & $90^{\circ} \pm 2.65^{\circ}$ & 0.40 & 32.7 \\
\hline 180000 & 205 & 1.132 & $90^{\circ} \pm 2.69^{\circ}$ & 0.41 & 32.6 \\
\hline 200000 & 227 & 1.132 & $90^{\circ} \pm 2.70^{\circ}$ & 0.41 & 32.5 \\
\hline
\end{tabular}

Fig. 6-8 show that the numerical results for the phase and polarization characteristics converge relatively fast with the increase of the number of applied tetrahedral mesh cells from 20000 to 100000 . The further increase of the number of used tetrahedral mesh cells from 100000 to 200000 results in much slower alteration and convergence of the phase and polarization characteristics.

Therefore, more than 100000 tetrahedral mesh cells per structure volume must be used, if the calculation of the waveguide polarizer's axial ratio and XPD is carried out by FEM in the frequency domain with the required accuracies of $0.5 \mathrm{~dB}$. In the case of application of FEM in the frequency domain with 100000 tetrahedral mesh cells the 
computation time of the waveguide polarizer's performance at the used for numerical analysis personal computer is equal to 100 seconds.

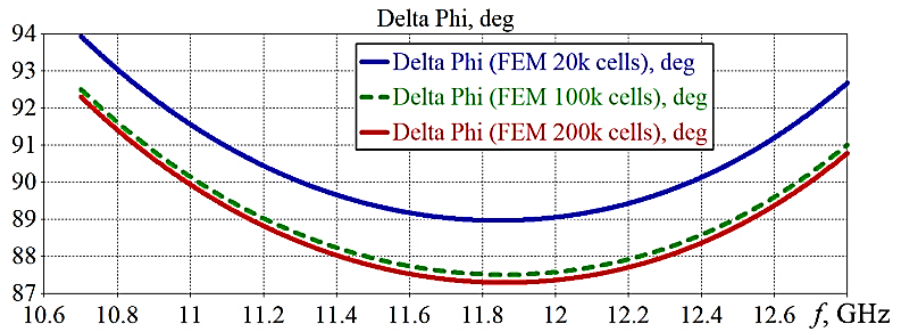

Fig. 6. Differential phase shift of the polarizer vs. frequency for different numbers of tetrahedral mesh cells used in FEM in the frequency domain

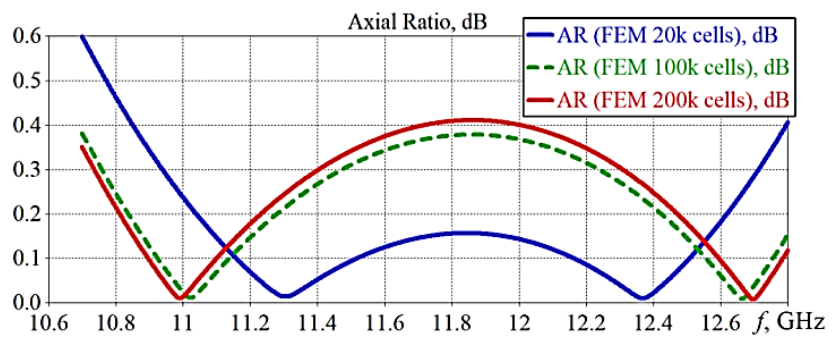

Fig. 7. Axial ratio of the waveguide iris polarizer vs. frequency for different numbers of tetrahedral mesh cells used in FEM in the frequency domain

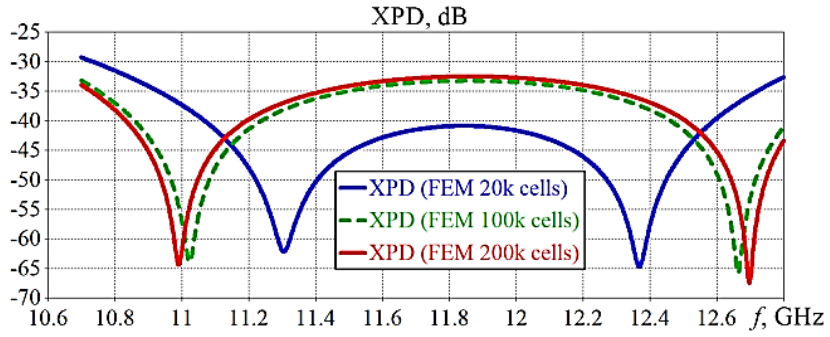

Fig. 8. XPD of the optimized waveguide iris polarizer vs. frequency for different numbers of tetrahedral mesh cells used in FEM in the frequency domain 


\section{Numerical simulation of waveguide iris polarizer using FDTD with different number of hexahedral mesh cells}

In this section we present the results of numerical simulations using FDTD at the grids with the number of hexahedral mesh cells from 100000 to 1500000 . The applied step of mesh increment was 100000 of hexahedral mesh cells. Table 2 presents the calculated by FDTD electromagnetic characteristics of the square waveguide iris polarizer and used computation time as dependences on the number of applied hexahedral mesh cells.

The analysis of Table 2 demonstrates that the computation time depends on the number of hexahedral mesh cells, which were applied in FDTD, approximately as the linear function. The convergence of the results for VSWR of both polarizations is extremely fast. This can be explained by the effective conformity of the applied Cartesian hexahedral mesh, which is used in calculations by FDTD, to the structure of a square waveguide iris polarizer. Thus, the calculation of VSWR of microwave devices, whose geometry is conformal to Cartesian grids, by FDTD is very accurate even at not dense hexahedral meshes. At coarse grid the VSWR maximum level is 1.134 and it rapidly converges to value of 1.132. Therefore, as the hexahedral mesh becomes more dense, the maximum level of VSWR slightly decreases.

As we can see in Table 2, the numerical calculation of differential phase shift, axial ratio and XPD of a waveguide iris polarizer at coarse grids is relatively inaccurate. Although the developed waveguide iris polarizer provides the required XPD higher than $32 \mathrm{~dB}$, the results of the calculations by FDTD at coarse grids from 100000 to 200000 hexahedral mesh cells predict XPD at the levels of 30-31 dB.

Table 2 demonstrates that the increase of number of hexahedral mesh cells from 100000 to 900000 leads to the decrease of axial ratio of the polarizer from $0.52 \mathrm{~dB}$ to $0.38 \mathrm{~dB}$ and to the simultaneous increase of its XPD from $30.5 \mathrm{~dB}$ to $33.2 \mathrm{~dB}$. Further increase of the number of hexahedral mesh cells from 900000 to 1500000 results in the slight increase of axial ratio of the developed polarizer from $0.38 \mathrm{~dB}$ to $0.40 \mathrm{~dB}$ and in the simultaneous decrease of its XPD from $33.2 \mathrm{~dB}$ to $32.8 \mathrm{~dB}$.

In Fig. 9-11 we presented the results of numerical calculations of the phase and polarization characteristics of the developed square waveguide iris polarizer using FDTD method. These figures demonstrate the comparison of the results obtained using the coarse hexahedral grid with 100000 mesh cells with the results found using the moderate mesh with 800000 tetrahedrons and with the ones calculated using the dense hexahedral grid with 1500000 mesh cells. 
Table 2

Characteristics of optimized waveguide polarizer and computation time vs. the number of hexahedral mesh cells applied in FDTD method

\begin{tabular}{|c|c|c|c|c|c|}
\hline $\begin{array}{c}\text { Number of } \\
\text { hexahedral } \\
\text { mesh cells }\end{array}$ & $\begin{array}{c}\text { Computation } \\
\text { time of FDTD, } \\
\text { seconds }\end{array}$ & $\begin{array}{c}\text { Maximum } \\
\text { level of } \\
\text { VSWR }\end{array}$ & $\begin{array}{c}\text { Differential } \\
\text { phase shift, }\end{array}$ & $\begin{array}{c}\text { Axial } \\
\text { ratio, } \\
\text { dB }\end{array}$ & $\begin{array}{c}\text { XPD, } \\
\text { dB }\end{array}$ \\
\hline 100000 & 24 & 1.134 & $90^{\circ} \pm 3.43^{\circ}$ & 0.52 & 30.5 \\
\hline 200000 & 34 & 1.132 & $90^{\circ} \pm 3.06^{\circ}$ & 0.46 & 31.5 \\
\hline 300000 & 57 & 1.132 & $90^{\circ} \pm 2.85^{\circ}$ & 0.43 & 32.1 \\
\hline 400000 & 79 & 1.132 & $90^{\circ} \pm 2.66^{\circ}$ & 0.40 & 32.7 \\
\hline 500000 & 95 & 1.132 & $90^{\circ} \pm 2.58^{\circ}$ & 0.39 & 32.9 \\
\hline 600000 & 118 & 1.132 & $90^{\circ} \pm 2.54^{\circ}$ & 0.39 & 33.1 \\
\hline 700000 & 144 & 1.132 & $90^{\circ} \pm 2.52^{\circ}$ & 0.38 & 33.1 \\
\hline 800000 & 165 & 1.132 & $90^{\circ} \pm 2.51^{\circ}$ & 0.38 & 33.1 \\
\hline 900000 & 194 & 1.132 & $90^{\circ} \pm 2.50^{\circ}$ & 0.38 & 33.2 \\
\hline 1000000 & 219 & 1.132 & $90^{\circ} \pm 2.55^{\circ}$ & 0.39 & 33.1 \\
\hline 1100000 & 243 & 1.132 & $90^{\circ} \pm 2.56^{\circ}$ & 0.39 & 33.0 \\
\hline 1200000 & 267 & 1.132 & $90^{\circ} \pm 2.58^{\circ}$ & 0.39 & 33.0 \\
\hline 1300000 & 293 & 1.132 & $90^{\circ} \pm 2.59^{\circ}$ & 0.39 & 32.9 \\
\hline 1400000 & 304 & 1.132 & $90^{\circ} \pm 2.61^{\circ}$ & 0.40 & 32.8 \\
\hline 1500000 & 322 & 1.132 & $90^{\circ} \pm 2.63^{\circ}$ & 0.40 & 32.8 \\
\hline
\end{tabular}

It is observed in Fig. 9-11 that the numerical results converge very fast with the increase of the number of hexahedral mesh cells from 100000 to 800000 . The further increase of the number of hexahedral mesh cells from 800000 to 1500000 results in much slower convergence of the phase and polarization characteristics.

Therefore, more than 800000 hexahedral mesh cells per structure volume must be applied, if the calculation of the waveguide polarizer's axial ratio and XPD is carried out using FDTD method with the required accuracies of $0.5 \mathrm{~dB}$. In the case of application of FDTD method with 800000 hexahedral mesh cells the computation time at the used for numerical analysis personal computer is equal to 165 seconds.

Finally, let us compare the numerical performance of FEM in the frequency domain and FDTD method for the calculation of characteristics of the waveguide iris polarizer. For this purpose, we unite 
and analyze several rows of Tables 1 and 2 containing results, which were computed at the same personal computer, into Table 3.

Table 3

Comparison of FEM in the frequency domain and FDFD method for calculation of the square waveguide iris polarizer characteristics

\begin{tabular}{|c|c|c|c|c|c|}
\hline $\begin{array}{c}\text { Computation } \\
\text { time of } \\
\text { FEM, } \\
\text { seconds }\end{array}$ & $\begin{array}{c}\text { Computation } \\
\text { time of FDTD, } \\
\text { seconds }\end{array}$ & $\begin{array}{c}\text { Number of } \\
\text { tetrahedral } \\
\text { mesh cells }\end{array}$ & $\begin{array}{c}\text { Number of } \\
\text { hexahedral } \\
\text { mesh cells }\end{array}$ & $\begin{array}{c}\text { Axial } \\
\text { ratio, } \\
\text { dB }\end{array}$ & $\begin{array}{c}\text { XPD, } \\
\text { dB }\end{array}$ \\
\hline 100 & 219 & 100000 & 1000000 & 0.39 & 33.1 \\
\hline 117 & 243 & 120000 & 1100000 & 0.39 & 33.0 \\
\hline 139 & 304 & 140000 & 1400000 & 0.40 & 32.8 \\
\hline
\end{tabular}

Table 3 demonstrates that for the same accuracy of numerical calculations of the phase and polarization characteristics of microwave waveguide devices the total computation time required by FEM in the frequency domain is more than 2 times less than the same total computation time required by the FDTD method. In addition, the corresponding number of tetrahedral mesh cells in FEM in the frequency domain is 10 times less, than the number of hexahedral mesh cells in the FDTD method. This leads to the lower requirements to the computer memory needed for the numerical calculations of microwave waveguide devices. Therefore, FEM in the frequency domain, which applies tetrahedral mesh, is more effective than the FDTD method for the calculation of electromagnetic characteristics of modern waveguide polarizers and other microwave devises for different applications.

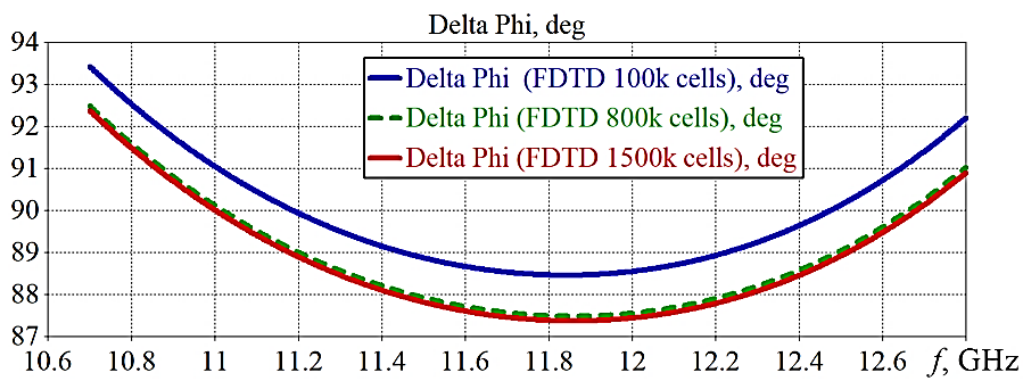

Fig. 9. Differential phase shift of the waveguide iris polarizer vs. frequency for different numbers of hexahedral mesh cells used in the FDTD method 


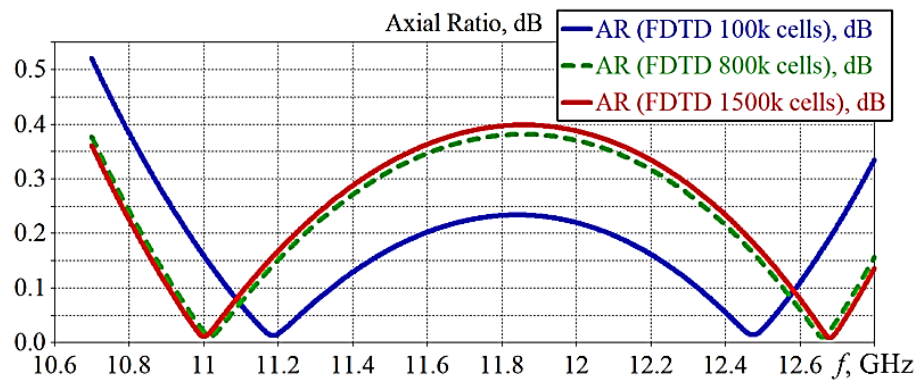

Fig. 10. Axial ratio of the optimized waveguide iris polarizer vs. frequency for different numbers of hexahedral mesh cells used in the FDTD method

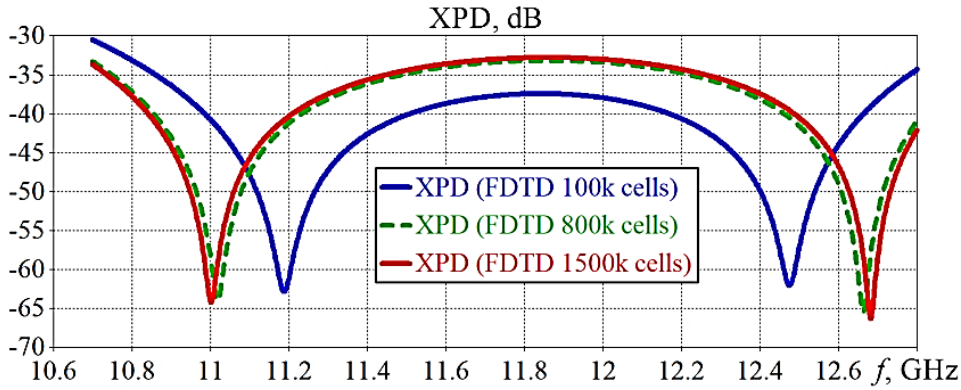

Fig. 11. XPD of the optimized waveguide iris polarizer vs. frequency for different numbers of hexahedral mesh cells used in the FDTD method

\section{CONCLUSIONS}

This research presents the results of performance comparison for two modern effective numerical methods: finite elements method (FEM) in the frequency domain and finite difference time domain (FDTD) method. Both methods were applied for the calculation of microwave waveguide iris polarizer for satellite antenna systems.

Obtained results show that more than 100000 tetrahedral mesh cells per structure volume must be used, if the calculation of the polarizer's axial ratio and XPD is carried out by FEM in the frequency domain with the accuracies of $0.5 \mathrm{~dB}$. More than 800000 hexahedral mesh cells per volume must be used, if the calculation of axial ratio and XPD is performed by FDTD method with the accuracies of $0.5 \mathrm{~dB}$. 
The computation time of FEM in the frequency domain is more than 2 times less than the time of calculations, which is required by FDTD method. In addition, the corresponding number of tetrahedral mesh cells of FEM in the frequency domain is 10 times less, than the number of hexahedral mesh cells of the FDTD method.

Therefore, FEM in the frequency domain, which applies tetrahedral mesh, provides much better numerical performance than the FDTD method. Thus, FEM in the frequency domain is suggested for the calculations of phase and polarization characteristics of modern waveguide polarizers and other microwave devises.

\section{SUMMARY}

In presented research we have analyzed and compared modern effective numerical techniques for the calculation of microwave devices performance. Nowadays, finite difference time domain method and finite elements method in the frequency domain are the most frequently applied numerical techniques, which are used for the simulation of electromagnetic fields in various antennas and bounded microwave structures. Modern modifications of these numerical methods and their pro and contras have been discussed. In addition, we have compared finite difference time domain technique and finite elements method in the frequency domain for the calculation of polarization and matching characteristics of microwave waveguide polarizers. Using this example we have found that the convergence of the calculated matching characteristics of microwave waveguide devices is fast for both considered numerical methods. On the other hand, the accuracy of numerical calculations of the phase and polarization characteristics is very sensitive to the number of mesh cells, at which the volume of the device structure is divided.

It was obtained that more than 100000 tetrahedral mesh cells per structure volume must be used, if calculation of the polarizer's axial ratio and crosspolar discrimination is carried out by finite elements method in the frequency domain with the accuracies of $0.5 \mathrm{~dB}$. If axial ratio and crosspolar discrimination must be calculated with the accuracies of $0.5 \mathrm{~dB}$ by the finite difference time domain method, then the application of more than 800000 hexahedral mesh cells per structure volume is required. It was found that the computation time of the finite elements method in the frequency domain is more than 2 times less than the computation time required by finite difference time domain method. The 
corresponding number of tetrahedral mesh cells in finite elements method in the frequency domain is 10 times less, than the number of hexahedral mesh cells in the finite difference time domain method.

Therefore, finite elements method in the frequency domain is more effective than the finite difference time domain method for the numerical calculations and optimization of modern waveguide polarizers and other microwave devises for various applications in radars, telecommunications and satellite information systems.

\section{REFERENCES}

1. Piltyay S.I., Sushko O.Yu., Bulashenko A.V., Demchenko I.V. Compact Ku-band iris polarizers for satellite telecommunication systems. Telecommunications and Radio Engineering. 2020. Vol. 79, No. 19. Pp. 1673-1690. DOI: 10.1615/TelecomRadEng.v79.i19.10.

2. Piltyay S.I., Bulashenko A.V., Demchenko I.V. Analytical synthesis of waveguide iris polarizers. Telecommunications and Radio Engineering. 2020. Vol. 79, No. 18. P. 1579-1597. DOI: 10.1615/TelecomRadEng.v79.i18.10.

3. Piltyay S.I., Bulashenko A.V., Demchenko I.V. Waveguide iris polarizers for Ku-band satellite antenna feeds. Journal of Nano- and Electronic Physics. 2020. Vol. 12, No. 5. P. 05024-1-5. DOI: 10.21272/jnep.12(5).05024.

4. Bulashenko A.V., Piltyay S.I., Demchenko I.V. Optimization of a polarizer based on a square waveguide with irises. Science-Based Technologies. 2020. Vol. 47, No. 3. P. 287-297. DOI: 10.18372/23105461.47.14878.

5. Piltyay S.I., Bulashenko A.V., Demchenko I.V. Compact polarizers for satellite information systems. IEEE Int. Conf. on Problems of Infocommunications. Science and Technology (PIC S\&T). Kharkiv, Ukraine, 2020. P. 350-355.

6. Bulashenko A.V., Piltyay S.I., Demchenko I.V. Analytical technique for iris polarizers development. IEEE Int. Conf. on Problems of Infocommunications. Science and Technology (PIC S\&T). Kharkiv, Ukraine, 2020. P. 464-469.

7. Piltyay S.I. High performance extended C-band $3.4-4.8 \mathrm{GHz}$ dual circular polarization feed system. XI International Conference on Antenna Theory and Techniques. Kyiv, Ukraine, 2017. P. 284-287. DOI: 10.1109/ICATT.2017.7972644. 
8. Dubrovka F.F., Piltyay S.I. A novel wideband coaxial polarizer. IX International Conference on Antenna Theory and Techniques. Odessa, Ukraine, 2013. Pp. 473-474. DOI: 10.1109/ICATT.2013.6650816.

9. Dubrovka F., Martunyuk S., Dubrovka R., Lytvyn M., Lytvyn S., Ovsianyk Yu., Piltyay S., et al. Circularly polarised X-band H11- and H21-modes antenna feed for monopulse autotracking ground station. IEEE UkrMW. Kharkiv, Ukraine, 2020, P. 196-202. DOI: 10.1109/UkrMW49653.2020.9252600.

10. Dubrovka F., Piltyay S., Sushko O., Dubrovka R., et al. Compact $\mathrm{X}$-band stepped-thickness septum polarizer. IEEE Ukrainian Microwave Week (UkrMW). Kharkiv, Ukraine, 2020, P. 135-138. DOI: $10.1109 /$ UkrMW49653.2020.9252583.

11.Dubrovka F.F., Piltyay S.I., Dubrovka R.R., Lytvyn M.M., Lytvyn S.M. Optimum septum polarizer design for various fractional bandwidths. Radioelectronics and Communications Systems. 2020. Vol. 63, No. 1. P. 15-23. DOI: 10.3103/S0735272720010021.

12. Bulashenko A.V., Piltyay S.I., Kalinichenko Y.I., Bulashenko O.V. Tunable square waveguide polarizer with irises and posts. Technical Engineering. 2020. Vol. 86, No. 2. P. 108-116. DOI: $10.26642 /$ ten-2020-2(86)-108-116.

13. Dubrovka F.F., Piltyay S.I. A high performance ultrawideband orthomode transducer and a dual-polarized quad-ridged horn antenna based on it. VIII International Conference on Antenna Theory and Techniques (ICATT). Kyiv, Ukraine, 2011. P. 176-178. DOI: 10.1109/ICATT.2011.6170737.

14.Dubrovka F.F., Piltyay S.I. Novel high performance coherent dual-wideband orthomode transducer for coaxial horn feeds. XI Int. Conf. on Antenna Theory and Techniques. Kyiv, Ukraine, 2017. P. 277280. DOI: 10.1109/ICATT.2017.7972642.

15.Piltyay S.I. Enhanced C-band coaxial orthomode transducer. Visnyk NTUU KPI. Seriia - Radiotekhnika, Radioaparatobuduvannia. 2014. Vol. 58. P. 27-34. DOI: 10.20535/RADAP.2014.58.27-34.

16. Dubrovka F.F., Piltyay S.I. Eigenmodes of coaxial quad-ridged waveguides. Numerical results. Radioelectronics and Communications Systems. 2014. Vol. 57, No. 2. P. 59-69. DOI: $10.3103 /$ S0735272714020010.

17. Dubrovka F.F., Piltyay S.I. Eigenmodes of sectoral coaxial ridged waveguides. Radioelectronics and Communications Systems. 2012. Vol. 55, No. 6. P. 239-247. DOI: 10.3103/S0735272712060015. 
18.Dubrovka F.F., Piltyay S.I. Eigenmodes of coaxial quad-ridged waveguides. Theory. Radioelectronics and Communications Systems. 2014. Vol. 57, No. 1. P. 1-30. DOI: 10.3103/S0735272714010014.

19.Dubrovka F.F., Piltyay S.I. Electrodynamics boundary problem solution for sectoral coaxial ridged waveguides by integral equation technique. Radioelectronics and Communications Systems. 2012. Vol. 55, No. 5. P. 191-203. DOI: 10.3103/S0735272712050019.

20.Dubrovka F.F., Piltyay S.I. Eigenmodes analysis of sectoral coaxial ridged waveguides by transverse field-matching technique. Part 1. Theory. Visnyk NTUU KPI. Seriia - Radiotekhnika, Radioaparatobuduvannia. 2013. Vol. 54. P. 13-23. DOI: 10.20535/RADAP.2013.54.13-23.

21.Piltyay S.I. Numerically effective basis functions in integral equation technique for sectoral coaxial ridged waveguides. 14-th International Conference on Mathematical Methods in Electromagnetic Theory (MMET). Kyiv, Ukraine, 2012. P. 492-495. DOI: 10.1109/MMET.2012.6331195.

22.Dubrovka F.F., Piltyay S.I. Eigenmodes analysis of sectoral coaxial ridged waveguides by transverse field-matching technique. Part 2. Numerical results. Visnyk NTUU KPI. Seriia - Radiotekhnika, Radioaparatobuduvannia. 2013. Vol. 55. P. 13-23. DOI: 10.20535/RADAP.2013.55.13-23.

23. Dubrovka F.F., Piltyay S.I. Boundary problem solution for eigenmodes in coaxial quad-ridged waveguides. Information and Telecommunication Sciences. 2014. Vol. 5, No. 1. P. 48-61. DOI: $10.20535 / 2411-2976.12014 .48-61$.

24.Dubrovka F.F., Piltyay S.I. Prediction of eigenmodes cutoff frequencies of sectoral coaxial ridged waveguides. Proceedings of International Conference on Modern Problem of Radio Engineering, Telecommunications and Computer Science (TCSET). Lviv-Slavske, Ukraine, 2012. P. 191.

25. Sakata Y., Mifune T., Matsuo T. Optimal subgrid connection for space-time finite integration technique. IEEE Transactions on Magnetics. 2017. Vol. 53, No. 6. DOI: 10.1109/TMAG.2017.2655626.

26. Sakata Y., Mifune T., Matsuo T. Optimal subgrid connection for space-time finite integration technique. IEEE Conference on Electromagnetic Field Computation (CEFC), P. 1, 2016. DOI: 10.1109/CEFC.2016.7816159.

27. Naydenko V., Piltyay S. Evolution of radiopulses radiated by Hertz's dipole in vacuum. 12-th International Conference on 
Mathematical Methods in Electromagnetic Theory (MMET). Odessa, Ukraine, 2008. Pp. 494-497. DOI: 10.1109/MMET.2008.4580972.

28. Liu N., Cai G., Zhu C., Huang Yu., Liu Q.H. The mixed finite element method with mass lumping for computing optical waveguide modes. IEEE Journal of Selected Topics in Quantum Electronics. 2015. Vol. 22, No. 2. DOI: 10.1109/JSTQE.2015.2473689.

29. Sun Q., Zhang R., Zhan Q., Liu Q. H. 3-D implicit-explicit hybrid finite difference/spectral element/finite element time domain method without a buffer zone. IEEE Trans. on Antennas and Propagation. 2019. Vol. 67, No. 8. Pp. 5469-5476. DOI: 10.1109/TAP.2019.2913740.

30. Bulashenko A. V. , Piltyay S. I. Equivalent microwave circuit technique for waveguide iris polarizers development. Visnyk NTUU KPI Seriia - Radiotekhnika Radioaparatobuduvannia. 2020. Vol. 83. P. 17-28. DOI: 10.20535/RADAP.2020.83.17-28.

31. Milligan T.A. Modern Antenna Design. Hoboken, New Jersey : John Wiley and Sons, 2005. $614 \mathrm{p}$.

\section{Information about authors:}

Piltyay S. I.,

Candidate of Engineering Sciences, Associate Professor at the Department of Theoretical Foundations

of Radio Engineering National Technical University of Ukraine "Igor Sikorsky Kyiv Polytechnic Institute" 37, Peremohy avenue, Kyiv, 03056, Ukraine

Bulashenko A. V., Senior Lecturer at the Department of Theoretical Foundations of Radio Engineering National Technical University of Ukraine "Igor Sikorsky Kyiv Polytechnic Institute" 37, Peremohy avenue, Kyiv, 03056, Ukraine 